\title{
Collaborative Evaluation Designs as an Authentic Course Assessment
}

\author{
Michelle Searle \\ Queen's University \\ Cheryl Poth \\ University of Alberta
}

\begin{abstract}
Strategies for optimizing evaluator education involve ongoing discussions within the field of evaluation. There remains unrealized potential for authentic assessments to support and measure learning that demonstrates the integration of evaluation theory with practice. In this practice note, we advance collaborative evaluation designs as a useful authentic assessment for generating the type of applied learning evidence required within an evaluation-focused graduate course. First, we provide a brief review of educational literature, highlighting the value of authentic assessments and a description of the contexts where we effectively applied the collaborative evaluation design. Next, we offer details of the four instructional processes involved in the authentic assessment: planning, development, feedback, and measurement. Finally, we advance lessons learned from our instructional experiences and the learner benefits of the collaborative evaluation design as an authentic assessment.
\end{abstract}

Keywords: assessment, post-secondary, teaching evaluation

Résumé : L'amélioration continue de la formation en évaluation dépend, en partie déchanges parmi ceux et celles qui en sont chargés. Il existe toujours un potentiel inexploité dévaluation authentique visant à appuyer et à mesurer l'apprentissage qui démontre l'intégration de la théorie et la pratique. Dans la présente note sur la pratique, nous présentons des modèles d'évaluation collaborative comme outils d'évaluation authentique et utile pour arriver au type de preuve d'apprentissage requis dans un cours de cycle supérieur en évaluation. Premièrement, nous faisons un bref examen de la littérature pédagogique, en soulignant la valeur des évaluations authentiques et une description des contextes dans lesquels nous avons appliqué efficacement le modèle dévaluation collaborative. Ensuite, nous décrivons de façon plus détaillée les quatre processus denseignement qui font partie d'une évaluation authentique : la planification, lélaboration, la rétroaction et la mesure. Finalement, nous faisons part des leçons apprises de notre expérience denseignement et des avantages, pour les apprenantes et apprenants, du modèle dévaluation collaborative comme évaluation authentique.

Mots clés : évaluation, postsecondaire, enseignement de l'évaluation

Corresponding author: Michelle Searle, Faculty of Education, Duncan McArthur Hall, 511 Union Street, Queen’s University, Kingston, ON, K7M 5R7; searlem@queensu.ca

C 2021 Canadian Journal of Program Evaluation / La Revue canadienne d'évaluation de programme 35.3 (Special Issue / Numéro spécial), 422-436 doi: 10.3138/cjpe.69691 
Strategies for optimizing evaluator education involve ongoing discussions within the field of evaluation (e.g., Chouinard et al., 2017; Gullickson et al., 2019; Poth et al., 2020; Trevisan, 2004). Post-secondary contexts are well known for their use of assessment strategies such as tests, quizzes, and essays to measure learning at the end of a course. While these strategies may be well suited for measuring learners' acquired knowledge of specific evaluation concepts, they may be insufficient for generating reliable and valid evidence of applications of complex evaluation skills in practice. The need for this type of learning experience is well established in the field; Gredler and Johnson (2001), for example, reflected on the value of directed evaluation experience as an adjunct to course-based work, citing the knowledge broadened by encountering real-world issues and the validation of emerging professional identities. Indeed, learners and instructors of evaluationfocused courses may well be better served by assessments that measure learning outcomes focused on the practical application of knowledge and skills (Knight, 2012). Yet there remains unrealized potential for authentic assessments within evaluation-focused coursework, evaluations that support and measure learning that demonstrates the integration of evaluation theory with practice.

As evaluation educators who have extensive training and experiences as instructors within K-12 and post-secondary education systems and who are well-established assessment scholars, we are well positioned for advancing the use of authentic assessments. We draw from our knowledge and research products highlighting the benefits of authentic assessment for both learners and instructors to bring the usefulness of authentic assessment into the dialogue of evaluator education. As one of the challenges of doing so is using field-specific terminology, and because prominent evaluators remind us that language matters (e.g. Hopson, 2000; Patton, 2000), we pause for a moment to clarify a key term.

While the word authentic is often used within educational literature to describe tasks, rubrics, and assessments that focus on real-world practice (Gulikers et al., 2008), we use the term authentic assessments to distinguish the generation of learning evidence within the integration of evaluation theory with practice. This usage aligns with that of Wiggins (1998) as a way to identify assessments when the learner is asked to complete a task that is highly similar to what they would encounter in their future professional practice. Authentic assessments within evaluator education place an emphasis on the learning processes that occur within real-world contexts and direct attention to the need for, and ways of, integrating feedback and reflection to extend learning. We advance authentic assessment as a term to be leveraged by evaluator educators to describe the processes involved in supporting and measuring desirable applied learning evidence that is specific to evaluation.

In this practice note, we advance collaborative evaluation designs as a useful authentic assessment for generating the type of applied learning evidence required within an evaluation-focused graduate course. First, we provide a brief review of educational literature, highlighting the value of authentic assessments and a description of the contexts where we effectively applied the collaborative evaluation 
design. Next, we offer details of the four instructional processes that involved the authentic assessment: planning, development, feedback, and measurement. Finally, we advance lessons learned from our instructional experiences and the learner benefits of the collaborative evaluation design as an authentic assessment.

\section{THE USEFULNESS OF AUTHENTIC ASSESSMENTS}

Within the landscape of educational assessments, authentic assessments are those in which learners are required to demonstrate combinations of knowledge, skills, and disposition in a real-life context (Maclellan \& Soden, 2004; Mueller, 2005; Wiggins, 1993). The value of authentic assessments is premised on research about situated learning (Stein, 1998) and social constructivist theory (Kalina \& Powell, 2009). Authentic assessments contribute to thinking about assessment as being integrated throughout the learning process; as described by Maclellan and Soden (2004), "within these perspectives, assessment is not only about judging how much people know but judging how, when and whether they use what they know" (p. 316). The benefits of this for evaluator education include directing learners' attention to what is valued-not just accumulated knowledge but also its application in real-world contexts. We frame seven key characteristics for authentic assessment:

1. involving learners in setting goals and assessment criteria;

2. performing a task, which includes locating resources to develop ideas and creating an artifact or product over time and in a real-world setting/ professional context;

3. engaging in continuous dialogue with others (e.g., peers, instructors, community partners) for the purpose of ongoing formative assessment;

4. using higher-level thinking and/or problem-solving skills;

5. integrating prior knowledge with inputs from classroom instruction and resources to create a product

6. demonstrating knowledge, skills, and attitudes related to a particular concept; and

7. advancing metacognitive, collaborative, and interpersonal skills as well as intellectual products (Airasian, 2001; Linn \& Miller, 2005; Wiggins, 1993).

We are not alone in our application of authentic assessments; indeed, their usefulness is well established in vocational training and competency-based programs where learners integrate theory and practice and move toward a mastery of skills needed in their future professional roles (Gulikers et al., 2008). Authentic assessments have been shown to positively affect learners' knowledge and motivation (e.g., Herrington \& Herrington, 1998; Raymond et al., 2013). Motivation may increase when assessments align with learners' perceptions for enhancing their knowledge and/or engaging in practical processes (Fook \& Sidhu, 2010; Gulikers 
et al., 2008). Surely learners and instructors would welcome the motivational and professional learning benefits of authentic assessments in evaluation-specific coursework.

\section{OUR TEACHING CONTEXTS FOR EVALUATION-FOCUSED AUTHENTIC ASSESSMENTS}

The collaborative evaluation design as an authentic assessment has become a key feature of our instructional approaches to teaching evaluation-focused courses at two Canadian institutions over the past decade. Its usefulness goes beyond its support and measurement of specific Canadian evaluator practice competencies (CES, 2018) to serve purposes similar to what is seen in community-service learning (Jacoby, 1996) and some internships (Divine et al., 2008), where service is rendered without payment because the learner completes an assignment for credit. Our courses are offered by faculties of education yet draw diverse learners from a range of disciplines. They are primarily delivered face-to-face in weekly three-hour classes and supported by online platforms across a 12-week term. Together we bring to these courses more than three decades of experience as practising evaluators with the Credentialed Evaluator (CE) designation and sustained programs of research in evaluation and evaluation education.

\section{OUR INSTRUCTIONAL PROCESSES}

Applying the collaborative evaluation design as an authentic assessment involves four instructional processes, represented in Figure 1: evaluation course and assessment planning, evaluation-focused instruction and learner development, learning supports and embedded feedback, and evaluation-specific learning and measurement.

\section{Evaluation course and assessment planning}

Planning a program evaluation course begins in the months, if not years, leading up to the course offering. As career educators, our pedagogical practices stem from core beliefs related to transformative learning theory (Mezirow, 1997) and constructivism (Duffy \& Jonassen, 1992). These theories inform the value we place on experience and reflection, both individually and with others, as essential for propelling learning.

Our planning is also influenced by the standards put forward by the Joint Committee (Yarbrough et al., 2011) and Canadian competencies (CES, 2018). These frameworks guide our expectations for learners and are interwoven in our assessments. Learners may develop an understanding of the standards of feasibility and utility while simultaneously expanding their competencies related to interpersonal and technical practice. Each learner experience is different, and neither the standards nor the competencies are meant to be used prescriptively; instead, they provide guiding ideas that we introduce and put into practice. Students 


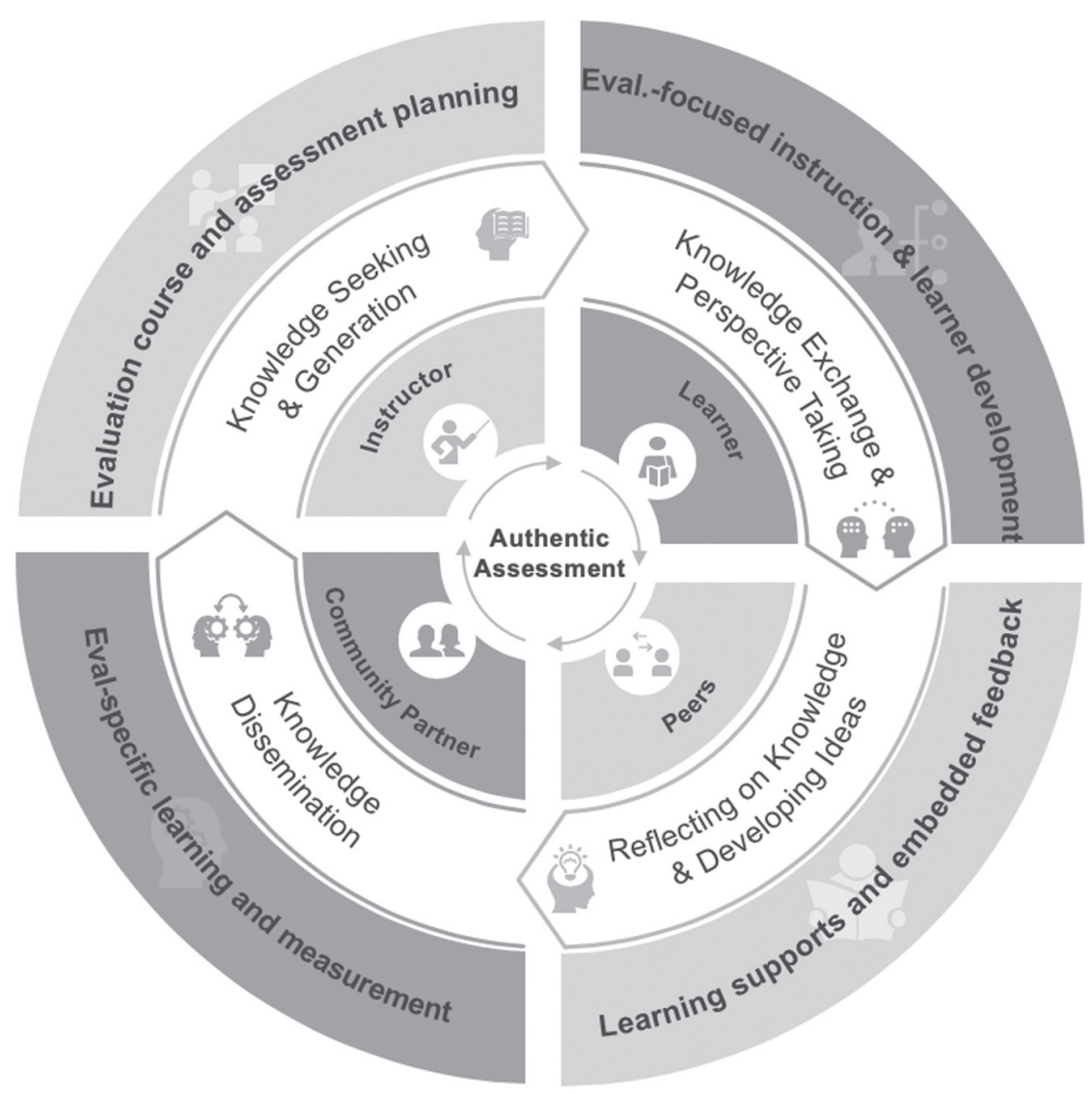

Figure 1. Four instructional processes involved in applying the collaborative evaluation design as an authentic assessment

monitor their thinking about these standards and competencies through selfassessment and through oral and written reflections during the course.

Initial planning for our course also involved new pragmatic procedures. Each instructor, for example, obtained ethical approval for gathering learner fieldwork and established a consent process to discuss fieldwork in class. This approval required the completion of standardized forms and resulted in documentation such as the "Community Partner Information Letter" and "A Guideline for Recruiting A Community Partner."

\section{Evaluation-focused instruction and learner development}

Instruction is varied and differentiated by learner needs and instructor strengths. Common to our courses is an understanding that, to effectively participate in collaborative evaluation design, learners require details about the expectations of 
the authentic assessment in advance. Details are offered in multiple forms (e.g., syllabus, slides, online, and orally) and reviewed for clarity. A sample of how this authentic assessment appears on one of the syllabi is provided in Table 1.

The collaborative evaluation design is submitted for grading at the end of course and thus contributes a high percentage of the overall grade calculation. The intention is to co-mingle theoretical understandings developed throughout the course with the practical experience of interacting with a community partner. A plethora of educational materials are offered to help learners translate theoretical learning to applied learning throughout the term. For example, Alkin and Vo's (2017) text is used as a pre-class reading to introduce core concepts and supplemented with additional required and optional readings each week; learners are expected to read as needed to be responsive to areas where they need development. Figure 2 shows a course timeline with different roles and a progression of activities. The sequence and interactions in this timeline are an idealized version; individual differences across different groups of learners are to be expected within a more generalized progression toward the end product.

\section{Learning supports and embedded feedback}

Students work independently or with a small group to identify and then work with a community partner for the course duration. Finding and securing the timely commitment of a community partner can be a daunting task. To facilitate this process, we offer supportive documentation and mitigate stress by offering the opportunity for students to work with known partners and in small groups. While locating a community partner is an essential task required in a short period of time, after years of offering these courses we have community partners that request to participate in this process, and we offer these contacts to students.

Together, the learner and partner develop evaluation priorities and questions. Regular contact is maintained in a way that suits the needs of the partner (e.g., email, phone, meetings). In an iterative process, the learner works with information gathered from their partner and from course resources (including instructor and peers) to shape the design. Exchanges between learner and community partner happen outside of class time without direct supervision from the instructor. Class time is allocated to discuss the designs in progress, and there is regular online activity.

Weekly classes typically include peer and instructor review of key elements, followed by questions and reflections related to designs and by time to imagine and act out "what-if" scenarios. Similar to what is described by Chouinard and colleagues (2017), learners reflect on the messiness of the experience, the back and forth, the communication, or other challenges. We emphasize that learner development takes place as knowledge is transformed into action through guided reflection and feedback. Feedback occurs in many ways and from multiple sources, informally from the partner, during class working sessions, and also through instructor conversations throughout the term online and in person. 


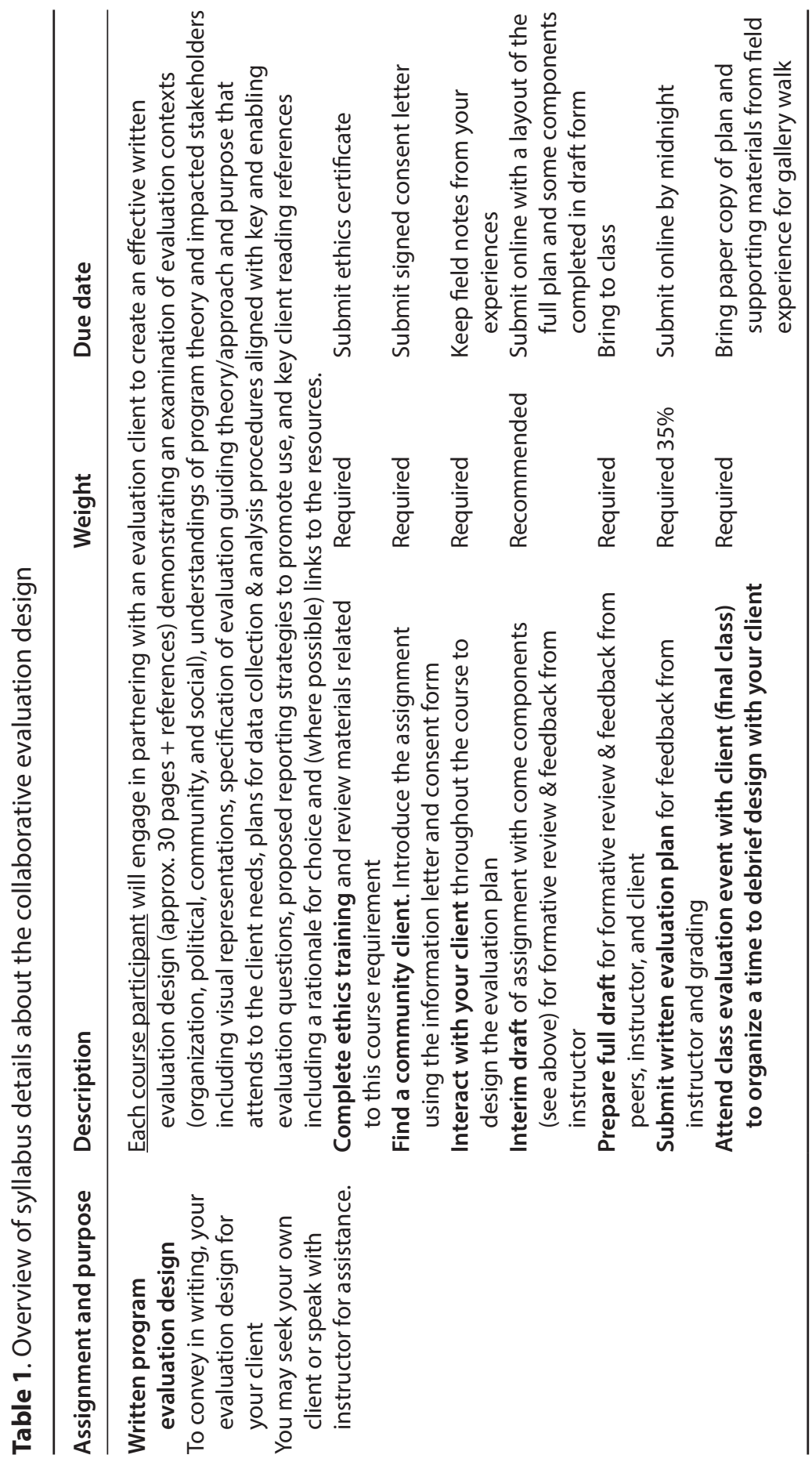




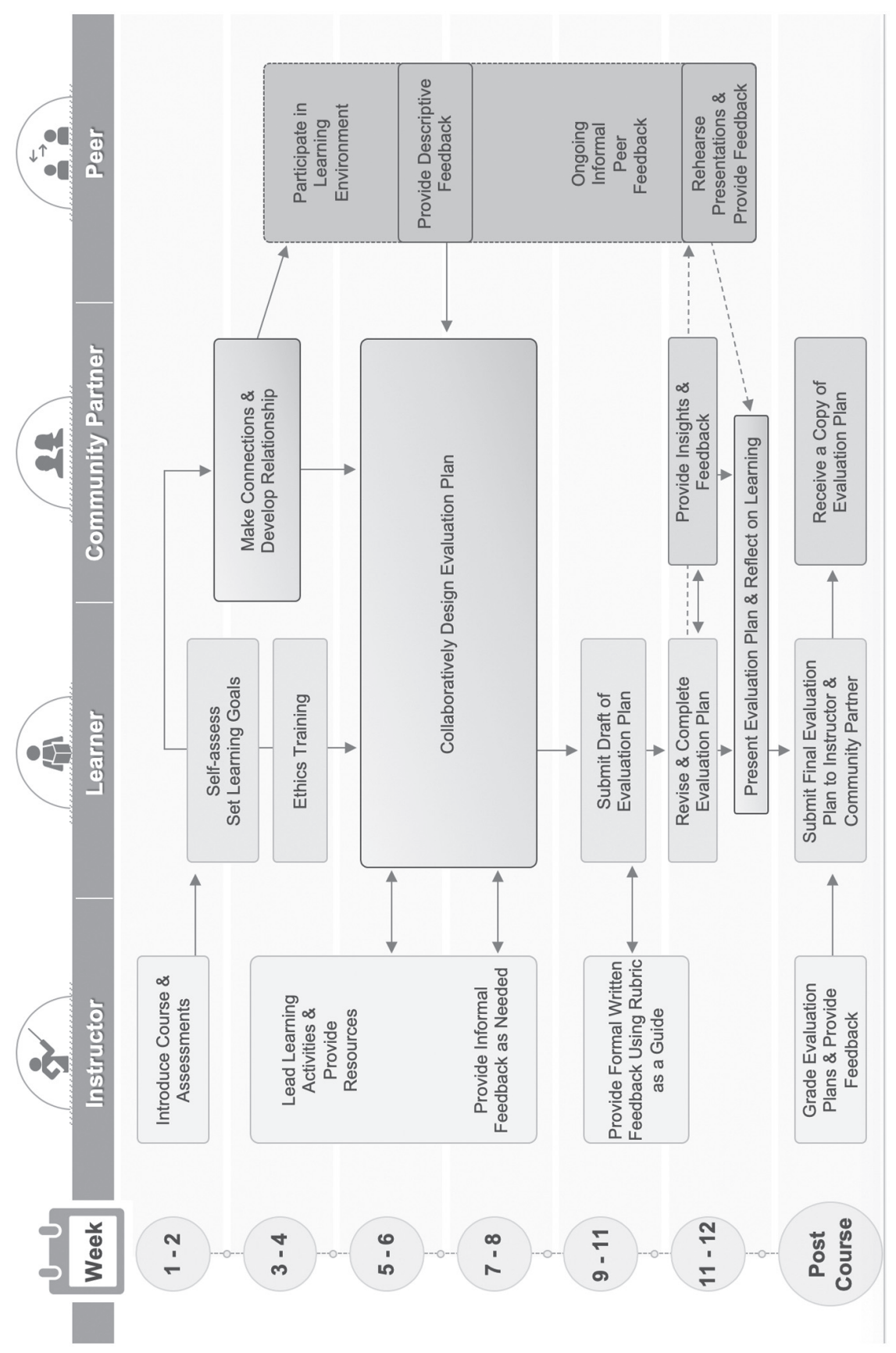

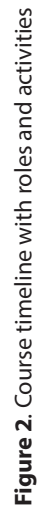




\section{Evaluation-specific learning and measurement}

Authentic assessment prioritizes evidence of learning developed over time and in diverse contexts to support sound decisions about development (DarlingHammond \& Snyder, 2000). From the start, we provide information about assessment and tools for individualized learning. We devised a self-assessment based on the Canadian competencies (CES, 2018) to encourage ownership of learning. Interacting with and receiving feedback from a community partner reinforces the real-world application of evaluation-specific knowledge, skills, and dispositions. Concurrently, opportunities to offer and receive feedback are embedded in the course and also emerge online. Feedback is a time-consuming but critical part of this course; instructors strive to offer comments that pose questions to provoke thinking.

As is consistent with classroom assessment theory that emphasizes learning, criteria are offered to learners and their initial feedback is collected (Sluijsmans, 2002). Past evaluation designs are offered mid-course for learners to explore the criteria. Working in pairs, learners use the criteria and ICE (Ideas, Connections, Extensions) model to assess the examples and identify how the designs could be strengthened (Fostaty-Young \& Wilson, 2000; Wilson, 1996). This same model is later used to measure their evaluation designs. Criteria include the following:

- constructions of visual and narrative representations of evaluation context, evaluation stakeholders, and descriptions of program theory;

- identification of evaluation type, theory/approach, and purposes;

- delineation of evaluation questions for addressing purpose;

- identification of data sources and of data collection and analysis procedures;

- $\quad$ proposed reporting strategies for promoting use;

- $\quad$ suggested resources; and

- overall communication.

Presentations happen during a final celebratory class that includes community partners. Each learner prepares a poster and gives a brief oral presentation to everyone before submitting the full design to partners and instructor. Outside of class time, learners repeat their self-assessment based on the CES competencies, paying attention to growth and reflecting on progress toward the initial goals. Although there is a substantial amount of assessment activity prior to final submissions, the focus of earlier assessments is formative, whereas submissions at the end of the course constitute a graded assessment as part of the learners' overall attainment.

\section{LESSONS LEARNED}

Reflecting on the use of an authentic assessment in our evaluation courses allows us to tease out and present thinking that had previously been implicit. In doing so, we identify three insights pertinent to the consideration of collaborative 
evaluation designs as an authentic assessment, and we relate our insights to our instructional processes and key characteristics of authentic assessments, described in Table 2. Common to the three insights is that everyone involved-instructor, learners, peers, and community partners-plays an essential role.

\section{Time commitment}

A commitment of time through the duration of the course is required for everyone involved. Without question, collaborative evaluation design with a community partner is an ambitious undertaking from an instructor's perspective, but the learning benefits make it well worthwhile. Time is necessary for instructors to engage in reflection upon their own professional and instructional experiences and to clearly communicate expectations to everyone involved. Given that graduate courses last only a few months, learners must immerse themselves quickly with decisive actions and skillfully navigate the project with their community partners. Learners are encouraged to draw from their past experiences and interweave insights from their other courses to assist with their progress.

Central to the success of this course is the quality of relationships. Since evaluation is not conducted in isolation, relationships must be nurtured within and beyond the class; these relationships are key to promoting learning over a sustained and complex task. While there is a danger of any of the required investments or budding relationships failing, this has not happened in either of our experiences. Instead, we have been able to support and/or pivot when difficulties arose, provide materials to proactively encourage learning, and intervene as needed. We suggest that our many positive experiences are related to our intentional balancing of time commitments throughout; this helps us teach and model the fact that patience and perseverance, with oneself and others, are always required while immersing in new learning and decision making throughout a collaborative evaluation design. While it is possible for some students to feel disillusioned, stressed, or overwhelmed, we maintain that a well-organized and facilitated authentic assessment with an investment of time and energy provides a low-risk, supportive learning environment for developing an evaluator's knowledge, skills, and competencies.

\section{Learning disposition}

A disposition for learning highlights the importance of being flexible and open to new experiences as an evaluator. When working in real-life contexts, learners, instructors, and community members benefit when they are attuned to and willing to embrace teachable moments. A teachable moment can include any of the variabilities, challenges, and successes of evaluation practice. These moments can arise in the form of a new leader, an emerging priority, a directive from a funder, a misplaced computer file, or even an unexpected weather occurrence! The outcome of these moments is similar: an opportunity to reflectively examine the situation and look for information to guide evaluation decision making.

Flexibility and openness also relate to an instructor's ability to recognize each learner's perspectives and experiences and to understand that different kinds of 


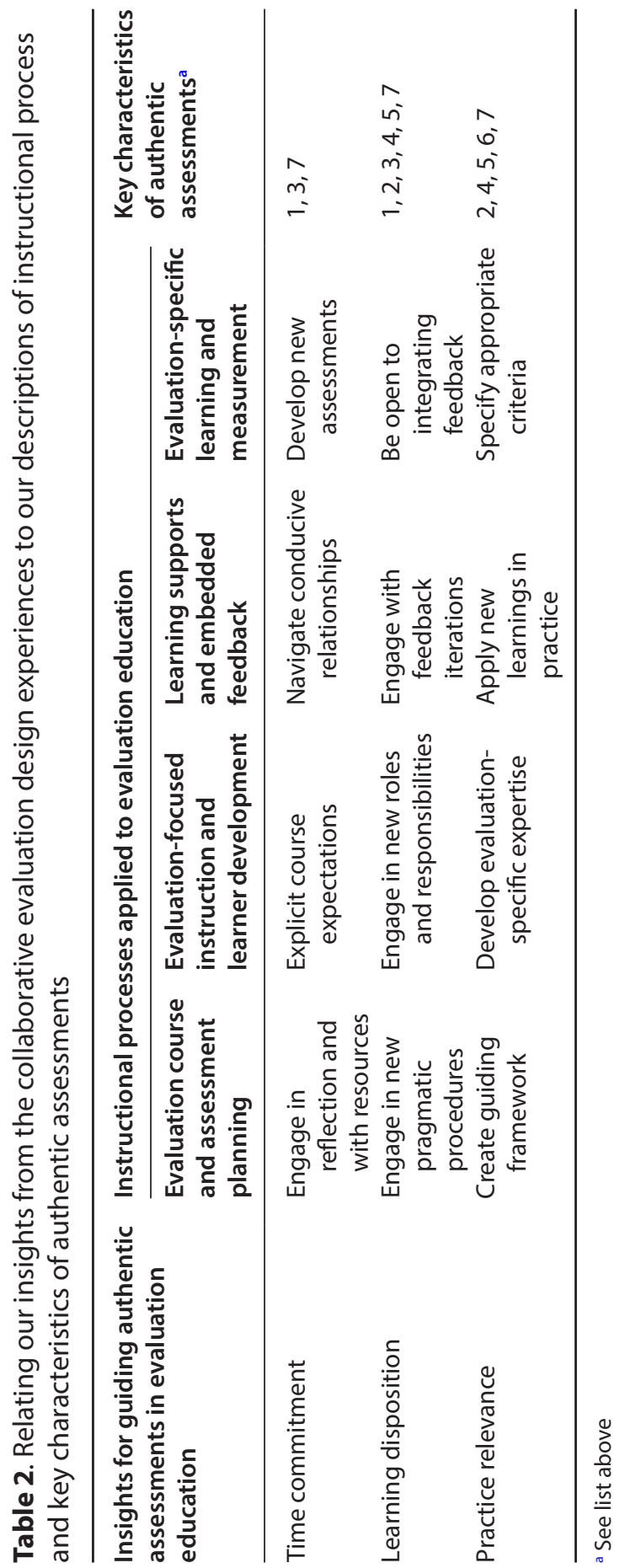


materials and feedback may be required to optimize growth. Opportunities for instructors to tailor teaching are enhanced when course planning allows for smallgroup discussions in class as well as the provision of supplementary materials and/ or detailed feedback online. When it comes to assessments, clear expectations and previewing of the ICE model provide guidance.

\section{Practice relevance}

Authentic assessments focus on maintaining professional relevance, and collaborative evaluation design is aligned with the knowledge, skills, and competencies required in evaluation. Additionally, many of the skills-planning, collaborating, thinking critically, accessing resources-are transferable to other professions. Learning from a theoretical course and operationalizing this learning in professional practice with a community partner is challenging; a range of skills and knowledge must be exhibited by the learner in coordination with the community partner and context, where the design is intended to be used.

At the end of the course, learners produce and present their product to showcase the knowledge they have developed. Learners are often nervous and proud, many are pleased with their efforts and also critical of their designs, and almost everyone is impressed by how much they have learned and accomplished throughout the course. The range of experiences and emotions in this authentic assessment aligns with the professional practice of evaluation. Importantly, learners are able to reflect and identify areas for future growth, and at the end of the course they seem themselves as professionals who have entered the field of evaluation.

To conclude, while several models for short-term projects within evaluation education have been described (e.g., Trevisan, 2004), we argue, similarly to Hurley and colleagues (2005), that learning in the field can provide a valuable experience for novice evaluators. We advance our collaborative evaluation design as prioritizing deep learning about evaluation standards, competencies, theories, and approaches while engaging in the real-world design of an evaluation. We recognize and advocate that no single course could expose a learner to the complexity or variety of evaluation encounters that a professional may experience. Instead, we encourage learners to use the metacognitive processes (e.g., reflective writing, self-assessment, and peer consultation) embedded within our courses to identify their strengths and areas for growth so as to continue to establish targets for ongoing evaluator learning.

We have discovered that authentic assessment allows for multiple kinds of knowledge and skills that are shaped by innumerable variables as learners transform their understanding into professional practice. Collaborative evaluation design has the strong potential for developing what Chouinard and colleagues (2017) refer to as an "epistemology of evaluation" (p. 495), where the interplay between theory and practice is experienced in authentic assessment. Integrating instructors, learners, community partners, and peers in reciprocal learning experiences may be construed as a form of boundary crossing, where collaboratively crafting the evaluation design creates the possibility for learning within 
individuals and groups, across a diversity of sites, both within and across institutions (Akkerman \& Bakker, 2011). We urge readers to consider the potential for a collaborative evaluation design or other form of authentic assessment as an essential form of evaluation education.

\section{REFERENCES}

Airasian, P. W. (2001). Classroom assessment: Concepts and applications. McGraw-Hill.

Akkerman, S. F., \& Bakker, A. (2011). Boundary crossing and boundary objects. Review of Educational Research, 81(2), 132-169. https://doi.org/10.3102/0034654311404435

Alkin, M. C., \& Vo, A. T. (2017). Evaluation essentials: From A to Z (2nd ed.). Guilford.

Canadian Evaluation Society (CES). (2018). Competencies for Canadian evaluation practice. http://www.evaluationcanada.ca/txt/2_competencies_cdn_evaluation_practice.pdf

Chouinard, J. A., Boyce, A. S., Hicks, J., Jones, J., Long, J., Pitts, R., \& Stockdale, M. (2017). Navigating theory and practice through evaluation fieldwork: Experiences of novice evaluation practitioners. American Journal of Evaluation, 38(4), 493-506. https://doi. org/10.1177/1098214016667582

Darling-Hammond, L., \& Snyder, J. (2000). Authentic assessment of teaching in context. Teaching and Teacher Education, 16(5-6), 523-545. https://doi.org/10.1016/s0742051x $(00) 00015-9$

Divine, R., Miller, R., Wilson, J. H., \& Linrud, J. (2008). Key philosophical decisions to consider when designing an internship program. Journal of Management and Marketing Research, 1(2), 1-8.

Duffy, T. M., \& Jonassen, D. H. (1992). Constructivism: New implications for instructional technology. Constructivism and the Technology of Instruction: A Conversation, 1, 1-16.

Fook, C. Y., \& Sidhu, G. K. (2010). Authentic assessment and pedagogical strategies in higher education. Journal of Social Sciences, 6(2), 153-161. https://doi.org/10.3844/jssp.2010.153.161

Fostaty Young, S., \& Wilson, R. J. (2000). Assessment and learning: The ICE approach. Portage and Main Press.

Gredler, M. E., \& Johnson, R. L. (2001). Lessons learned from the directed evaluation experience. American Journal of Evaluation, 22(1), 97-104. https://doi.org/10.1016/ s1098-2140(01)00115-1

Gulikers, J. T. M., Bastiaens, T. J., Kirschner, P. A., \& Kester, L. (2008). Authenticity is in the eye of the beholder: Student and teacher perceptions of assessment authenticity. Journal of Vocational Education and Training, 60(4), 401-412. https://doi. org/10.1080/13636820802591830

Gullickson, A. M., King, J., LaVelle, J. M., \& Clinton, J. (2019). The current state of educating evaluators: A situation analysis and call to action. Evaluation and Program Planning, 75, 20-30. https://doi.org/10.1016/j.evalprogplan.2019.02.012

Herrington, J., \& Herrington, A. (1998). Authentic assessment and multimedia: How university students respond to a model of authentic assessment. Higher Education Research \& Development, 17(3), 305-322. https://doi.org/10.1080/0729436980170304

Hopson, R. K. (2000). How and why language matters in evaluation. New Directions for Evaluation, 86, 1-115. 
Hurley, C., Renger, R., \& Brunk, B. (2005). Learning from a challenging fieldwork evaluation experience: Perspectives of a student and an instructor. American Journal of Evaluation, 26(4), 562-578. https://doi.org/10.1177/1098214005281323

Jacoby, B. (1996). Service-learning in higher education: Concepts and practices. The JosseyBass Higher and Adult Education Series. Jossey-Bass Publishers.

Kalina, C., \& Powell, K. C. (2009). Cognitive and social constructivism: Developing tools for an effective classroom. Education, 130(2), 241-250.

Knight, P. (2012). Assessment for learning in higher education. Routledge.

Linn, R., \& Miller, M. D. (2005). Measurement and evaluation in teaching. Merrill.

Maclellan, E., \& Soden, R. (2004). The importance of epistemic cognition in studentcentred learning. Instructional Science, 32(3), 253-268. https://doi.org/10.1023/ b:truc.0000024213.03972.ce

Mezirow, J. (1997). Transformative learning: Theory to practice. New Directions for Adult and Continuing Education, 1997(74), 5-12. https://doi.org/10.1002/ace.7401

Mueller, J. (2005). The authentic assessment toolbox: Enhancing student learning through online faculty development. Journal of Online Learning and Teaching, 1(1), 1-7.

Patton, M. Q. (2000). Overview: Language matters. New Directions for Evaluation, 2000(86), 5-16. https://doi.org/10.1002/ev.1168

Poth, C. N., \& Searle, M., Aquilina, A. M., Ge, J., \& Elder, A. (2020). Using the CIPP model to assess the impact of a competency-based approach to evaluation education: A case study of the student experience in a Canadian graduate course. Evaluation and Program Planning, 79, Article 101789. https://doi.org/10.1016/j.evalprogplan.2020.101789

Raymond, J. E., Homer, C. S. E., Smith, R., \& Gray, J. E. (2013). Learning through authentic assessment: An evaluation of a new development in the undergraduate midwifery curriculum. Nurse Education in Practice, 13(5), 471-476. https://doi.org/10.1016/j. nepr.2012.10.006

Sluijsmans, D. (2002). Student involvement in assessment: The training of peer assessment skills (Unpublished doctoral dissertation). Open University of the Netherlands, Heerlen, The Netherlands.

Stein, D. (1998). Situated learning in adult education (pp. 195-202). ERIC Clearinghouse on Adult, Career, and Vocational Education, Center on Education and Training for Employment, College of Education, The Ohio State University.

Trevisan, M. S. (2004). Practical training in evaluation: A review of the literature. American Journal of Evaluation, 25(2), 255-272. https://doi.org/10.1177/109821400402500212

Wiggins, G. P. (1993). Assessing student performance: Exploring the purpose and limits of testing. Jossey-Bass.

Wiggins, G. P. (1998). Educative assessment: Designing assessments to inform and improve student performance. Jossey-Bass Publishers.

Wilson, R. J. (1996). Assessing students in classrooms and schools. Allyn \& Bacon.

Yarbrough, D. B., Shulha, L. M., Hopson, R. K., \& Caruthers, F. A. (2011). The program evaluation standards: A guide for evaluators and evaluation users (3rd ed.). Sage. 


\section{AUTHOR INFORMATION}

Michelle Searle is an assistant professor of Educational Evaluation at Queen's University. She holds the Credentialed Evaluator (CE) designation from the Canadian Evaluation Society and is a member of the Ontario College of Teachers (OCT). Michelle focuses on increasing the usefulness of program evaluation through a collaborative approaches and innovative forms of dissemination.

Cheryl Poth is professor in the Centre for Applied Measurement and Evaluation in the Department of Educational Psychology, Faculty of Education, University of Alberta, and a co-founder of the Alberta Clinical and Community-Based Evaluation Research Team. Her research interests include evaluation use with particular emphasis on developmental, participatory, and collaborative evaluation approaches. 